\title{
Different variations of tissue B-group vitamin concentrations in short- and long-term starved rats
}

\author{
Aya Moriya ${ }^{1}$, Tsutomu Fukuwatari ${ }^{1,2}$, Mitsue Sano ${ }^{1,2}$ and Katsumi Shibata ${ }^{1,2 *}$ \\ ${ }^{1}$ Division of Life Style Studies, Section of Nutritional Sciences, Graduate School of Human Cultures, The University of Shiga \\ Prefecture, 2500 Hassaka, Hikone, Shiga 522-8533, Japan \\ ${ }^{2}$ Department of Food Science and Nutrition, Graduate School of Human Cultures, The University of Shiga Prefecture, \\ 2500 Hassaka, Hikone, Shiga 522-8533, Japan \\ (Received 3 November 2010 - Revised 24 March 2011 - Accepted 25 March 2011 - First published online 27 June 2011)
}

\section{Abstract}

Prolonged starvation changes energy metabolism; therefore, the metabolic response to starvation is divided into three phases according to changes in glucose, lipid and protein utilisation. B-group vitamins are involved in energy metabolism via metabolism of carbohydrates, fatty acids and amino acids. To determine how changes in energy metabolism alter B-group vitamin concentrations during starvation, we measured the concentration of eight kinds of B-group vitamins daily in rat blood, urine and in nine tissues including cerebrum, heart, lung, stomach, kidney, liver, spleen, testis and skeletal muscle during $8 \mathrm{~d}$ of starvation. Vitamin $\mathrm{B}_{1}$, vitamin $\mathrm{B}_{6}$, pantothenic acid, folate and biotin concentrations in the blood reduced after 6 or $8 \mathrm{~d}$ of starvation, and other vitamins did not change. Urinary excretion was decreased during starvation for all B-group vitamins except pantothenic acid and biotin. Less variation in B-group vitamin concentrations was found in the cerebrum and spleen. Concentrations of vitamin $\mathrm{B}_{1}$, vitamin $\mathrm{B}_{6}$, nicotinamide and pantothenic acid increased in the liver. The skeletal muscle and stomach showed reduced concentrations of five vitamins including vitamin $B_{1}$, vitamin $B_{2}$, vitamin $B_{6}$, pantothenic acid and folate. Concentrations of two or three vitamins decreased in the kidney, testis and heart, and these changes showed different patterns in each tissue and for each vitamin. The concentration of pantothenic acid rapidly decreased in the heart, stomach, kidney and testis, whereas concentrations of nicotinamide were stable in all tissues except the liver. Different variations in B-group vitamin concentrations in the tissues of starved rats were found. The present findings will lead to a suitable supplementation of vitamins for the prevention of the re-feeding syndrome.

\section{Key words: Starvation: Fasting: Energy metabolism}

Starvation produces a series of metabolic changes that lead to a reduction in body weight, alterations in body composition and metabolic gene expression ${ }^{(1,2)}$. In mammals and birds, three distinct levels of energy depletion have been established $^{(3-10)}$. The first phase (phase 1) is a rapid period of adaptation marked by an increase in mobilisation of fat stores and a lowering in protein utilisation. During the second phase (phase 2), which is a long period of thrift, most of the energy expenditure is derived from fats, and then fat stores are progressively exhausted, while body proteins are efficiently spared. The third phase (phase 3) is characterised by an increase in protein utilisation. In humans, the negative energy balance resulting from starvation can arise due to disease, eating or psychological disorders, or hunger strikes. Starvation and consequent re-feeding syndrome can lead to electrolyte disorders, especially hypophosphataemia, along with neurological, pulmonary, cardiac, neuromuscular and haematological complications ${ }^{(11)}$. To avoid the re-feeding syndrome, an additional load of vitamins has been suggested to correct the vitamin deficiencies $^{(11)}$. However, little is known about B-group vitamin status during starvation.

Several B-group vitamins take part in energy metabolism. For instance, vitamin $\mathrm{B}_{2}$ functions as FAD and FMN in redox reactions including the electron transport chain and fatty acid oxidation. Nicotinamide is involved in more than 200 reactions, including the metabolism of carbohydrates, amino acids and fatty acids, and also in the electron transport chain. Vitamin $\mathrm{B}_{1}$ catalyses carbohydrate metabolism including decarboxylation of $\alpha$-ketoacids and trans-ketolation as a cofactor thiamin diphosphate; vitamin $\mathrm{B}_{6}$ functions as pyridoxal 5'-phosphate in amino acid metabolism including aminotransferases,

Abbreviations: 2-Py, $\quad N^{1}$-methyl-2-pyridone-5-carboxamide; 4-Py, $N^{1}$-methyl-4-pyridone-5-carboxamide; 3-HBA, 3-hydroxybutyric acid; MNA, $N^{1}$-methylnicotinamide.

*Corresponding author: K. Shibata, fax +81 74928 8499, email kshibata@shc.usp.ac.jp 
decarboxylases, racemases and dehydratases as pyridoxal 5'-phosphate; and pantothenic acid is involved in fatty acid metabolism such as oxidation and synthesis. For these reasons, in the 'Dietary Reference Intakes for Japanese, 2010', dietary requirements for vitamin $B_{1}$, vitamin $B_{2}$ and niacin are expressed per $4186 \mathrm{~kJ}(1000 \mathrm{kcal})$, and the requirement for vitamin $B_{6}$ is expressed in terms of protein intake ${ }^{(12)}$.

As mentioned earlier, prolonged starvation sifts the energy source from glucose to fats and then to protein, and B-group vitamins are involved in the metabolism of carbohydrates, fatty acids and amino acids. Thus, in the present study, we investigated how changes in energy metabolism altered B-group vitamin utilisation during starvation. We comprehensively determined eight kinds of B-group vitamin concentrations in rat blood, urine and tissues including the brain, heart, lung, stomach, kidney, liver, spleen, testis and skeletal muscle during $8 \mathrm{~d}$ of starvation.

\section{Materials and methods}

\section{Diets}

The composition of the purified diet is shown in Table 1. Vitamin-free milk casein, L-methionine and sucrose were purchased from Wako Pure Chemical Industries Limited (Osaka, Japan). Maize oil was purchased from Nisshin OilliO Group, Limited (Tokyo, Japan). Gelatinised maize starch, the mineral mixture (AIN-93G) and the vitamin mixture (AIN-93VX) were obtained from Oriental Yeast Company, Limited (Tokyo, Japan).

\section{Animals}

Male rats of the Wistar strain, weighing 225-235g, were obtained from CLEA Japan, Inc. (Tokyo, Japan). The rats were individually housed in a temperature-controlled room $\left(22 \pm 2^{\circ} \mathrm{C}\right.$ and $50-60 \%$ humidity) with a $12 \mathrm{~h}$ light $-12 \mathrm{~h}$ dark cycle and were allowed to acclimate to the environment for $7 \mathrm{~d}$ before starting the experiment. Body mass, food consumption and water intake were recorded daily $( \pm 0 \cdot 1 \mathrm{~g})$. We also collected $24 \mathrm{~h}$ urine samples every day.

\section{Experimental procedures}

A total of twenty-five rats were randomly divided into five groups. After 1 week of acclimatisation, five rats were killed

Table 1. Composition of the diet

\begin{tabular}{lc}
\hline & $(\mathrm{g} / 100 \mathrm{~g})$ \\
\hline Vitamin-free milk casein & 20.0 \\
L-Met & 0.2 \\
Gelatinised maize starch & 46.9 \\
Sucrose & 23.4 \\
Maize oil & $5 \cdot 0$ \\
Mineral mixture (AIN-93-G) & 3.5 \\
Vitamin mixture (AIN-93VX) & 1.0 \\
\hline
\end{tabular}

* The composition of the vitamin mixture is described by Reeves et al. ${ }^{(13)}$. by decapitation as a control group (CONT, $n$ ). The other rats were deprived from food for $1 \mathrm{~d}(\mathrm{~S} 1, n 5), 2 \mathrm{~d}(\mathrm{~S} 2, n 5)$, $6 \mathrm{~d}(\mathrm{~S} 6, n 5)$ or until they had been in phase 3 for $2 \mathrm{~d}$; that is, they were starved for a total duration of $6-9 \mathrm{~d}(\mathrm{P} 3, n 5)$. The starving phase was determined by calculating the specific daily rate of body mass loss $\mathrm{d} M / M \mathrm{~d} t$ (g/kg per $\mathrm{d}$ ) for each animal ( $\mathrm{d} M$ represents the loss of body mass during $\mathrm{d} t=t_{1}-t_{0}$ and $M$ is the body mass of the rat at $t_{0}{ }^{(10,14)}$. Blood was taken from the tail vein at 09.00 hours every day, and 3-hydroxybutyric acid (3-HBA) concentration in the blood was measured with a 3-HBA Kit (Abbott Japan Company, Limited, Tokyo, Japan) to confirm the metabolic state of each animal because blood 3-HBA reflects fatty acid oxidation.

After the animals were killed, blood samples were collected into EDTA-2K tubes from the carotid artery and were centrifuged at $1700 \mathrm{~g}$ for $10 \mathrm{~min}$ at $4^{\circ} \mathrm{C}$. Plasma glucose, TAG, urea $\mathrm{N}$, aspartate aminotransferase and alanine aminotransferase were measured with FUJI DRI-CHEM (FUJIFILM Company, Tokyo, Japan).

The cerebrum, heart, lungs, stomach, kidneys, liver, spleen, testes and leg muscles were dissected and weighed $( \pm 0.001 \mathrm{~g})$. The stomach was cleared of its contents. All tissue samples were immediately homogenised in ultra-pure water at 1:10 (w/v) using a Teflon glass homogeniser and stored at $-20^{\circ} \mathrm{C}$ until needed. The present study was conducted according to the guidelines for the care and use of laboratory animals, and was approved by the Ethics Committee of the University of Shiga Prefecture (Shiga, Japan).

\section{Analytical methods}

Vitamin $B_{1}$. Thiamin in urine was measured directly. The vitamin $\mathrm{B}_{1}$ content in the blood and tissue was determined as the sum of thiamin, thiamin monophosphate and thiamin diphosphate and was expressed as total thiamin. TCA (5\%) was added to whole blood and tissue homogenates, and the blood and homogenates were centrifuged for $5 \mathrm{~min}$ at $20000 \mathbf{g}$, and the supernatant of the mixture was used for measurement. Vitamin $\mathrm{B}_{1}$ levels in the urine, blood and tissue were determined by the HPLC post-labelled fluorescence method ${ }^{(15)}$.

Vitamin $B_{2}$. Riboflavin in urine was measured directly by HPLC $^{(16)}$. Riboflavin, FMN and FAD in blood and tissue were converted to lumiflavin by photolysis. Briefly, the supernatant from a TCA-treated blood or tissue sample was added to an equal volume of $1 \mathrm{M}-\mathrm{NaOH}$. The alkalised mixture was irradiated with a fluorescent lamp for $30 \mathrm{~min}$, and acetic acid was added to the mixture. The neutralised mixture was filtered with a $0.45 \mu \mathrm{m}$ microfilter and the filtrate was directly injected into the HPLC system for the measurement of lumiflavin ${ }^{(17)}$. The measured lumiflavin was expressed as total vitamin $\mathrm{B}_{2}$.

Vitamin $B_{6}$. 4-Pyridoxic acid, a catabolite of vitamin $\mathrm{B}_{6}$, in urine was measured directly by $\operatorname{HPLC}^{(18)}$. Serum pyridoxal and pyridoxal 5'-phosphate were determined by the HPLC method $^{(19)}$. Vitamin $\mathrm{B}_{6}$ vitamers, including phosphate esters in the tissue, were converted to free vitamin $B_{6}$ vitamers such as pyridoxal and pyridoxamine using an autoclave under acidic conditions. Briefly, the homogenate was added 
to $0.06 \mathrm{M}-\mathrm{HCl}$ at $1: 8(\mathrm{v} / \mathrm{v})$ and autoclaved at $121^{\circ} \mathrm{C}$ for $3 \mathrm{~h}$, and the mixture was adjusted to $\mathrm{pH} 5.0$ using $1 \mathrm{M}-\mathrm{NaOH}$. These were measured as total vitamin $\mathrm{B}_{6}$ by the microbioassay method using Saccharomyces carlsbergensis strain 4228 ATCC $9080^{(20)}$.

Vitamin $B_{12}$. Urine, plasma and tissue homogenates were added to a $0.2 \mathrm{~mm}$-acetate buffer ( $\mathrm{pH} 4.8$ ) with $0.0006 \%$ potassium cyanide. These were put into a boiling water bath for $5 \mathrm{~min}$ to be converted to cyanocobalamin, and then $10 \%$ metaphosphoric acid was added to be neutralised. Cyanocobalamin was determined by the microbioassay method using Lactobacillus leichmannii ATCC $7830^{(21)}$.

Niacin. Nicotinamide ${ }^{(22)}$ and its catabolites, $N^{1}$-methylnicotinamide $(\mathrm{MNA})^{(23)}, \quad N^{1}$-methyl-2-pyridone-5-carboxamide (2-Py) and $N^{1}$-methyl-4-pyridone-3-carboxamide (4-Py) ${ }^{(22)}$, in urine were measured directly by HPLC. For measuring the total nicotinamide content in blood and tissues, the whole blood and tissue homogenates were autoclaved at $121^{\circ} \mathrm{C}$ for $20 \mathrm{~min}$ to convert the coenzymes to nicotinamide. The resulting nicotinamide was then determined by the HPLC method ${ }^{(22,24)}$.

Pantothenic acid. Pantothenic acid in urine was determined by HPLC ${ }^{(25)}$. To digest the bound pantothenic acid including coenzyme A and phosphopantetheine in tissue and plasma to free form, the homogenate or blood was incubated at $37^{\circ} \mathrm{C}$ for $24 \mathrm{~h}$. Pantothenic acid in the plasma and tissue was determined by the microbioassay method using Lactobacillus plantarum ATCC $8014^{(26)}$.

Folate. Folate in urine and plasma was directly determined by the microbioassay method using Lactobacillus casei ATCC $27773^{(27)}$. Folate in tissues was digested to monoglutamate forms by treatment with protease and conjugase. Briefly, $1 \mathrm{M}-\mathrm{KH}_{2} \mathrm{PO}_{4}-\mathrm{K}_{2} \mathrm{HPO}_{4}$ buffer ( $\mathrm{pH}$ 6.1) was added to the tissue homogenate at $1: 9(\mathrm{v} / \mathrm{v})$, and the homogenate was autoclaved at $121^{\circ} \mathrm{C}$ for $5 \mathrm{~min}$. Proteinase MS (Kaken Pharmaceutical Company, Limited, Tokyo, Japan) was added to the homogenate at a final concentration of $2.5 \mathrm{mg} / \mathrm{ml}$ and then incubated at $37^{\circ} \mathrm{C}$ for $3 \mathrm{~h}$. The reaction mixture was added to the conjugase solution (extract from porcine kidney acetone powder, Sigma, Porcine, Type II) at 30:1 (v/v) and incubated at $37^{\circ} \mathrm{C}$ for $12 \mathrm{~h}$. After centrifugation at $10000 \mathrm{~g}$ for $10 \mathrm{~min}$, the supernatant was used for determination by the microbioassay.

Biotin. Bound biotin in tissues was converted to the free form using autoclave under acidic conditions. Briefly, $1.5 \mathrm{M}-\mathrm{H}_{2} \mathrm{SO}_{4}$ was added to the homogenate at $1: 1(\mathrm{v} / \mathrm{v})$, and the homogenate was autoclaved for $1 \mathrm{~h}$ at $121^{\circ} \mathrm{C}$. The suspension was centrifuged at $10000 \mathrm{~g}$ for $10 \mathrm{~min}$ at $4^{\circ} \mathrm{C}$, and the supernatant was used to measure biotin. Biotin in urine and plasma was measured directly. The biotin content in urine, plasma and tissue was determined by the microbioassay method using L. plantarum ATCC $8014^{(28)}$.

\section{Statistical analysis}

Values are expressed as means with their standard errors. P3 rats (starved for 6-9d) were expressed at $8 \mathrm{~d}$ on the graph for convenience. To test the significance of the differences in mean values among all groups, one-way ANOVA with Tukey's post hoc test was employed. Repeated ANOVA with Bonferroni's post hoc test was used to analyse urinary excretion of B-group vitamins in P3 rats, and individual data points were compared with their data at day 0 . All differences at $P<0.05$ were considered to be statistically significant. Prism software (version 5; obtained from GraphPad Software, Inc., San Diego, CA, USA) was used for all analyses.

\section{Results}

\section{Changes in body mass during starvation}

Changes in body mass during starvation are shown in Table 2. Starvation for the first $24 \mathrm{~h}$ produced a weight loss of $7 \%$. From the second day to the last day of starvation, the rats lost $5 \%$ weight for each $24 \mathrm{~h}$ (data not shown). The specific daily rate of body mass loss $(\mathrm{d} M / M \mathrm{~d} t) v$. time in starved rats is presented in Fig. 1. The pattern of $\mathrm{d} M / \mathrm{d} M t$ showed a

Table 2. Body mass and organ mass in the control and starved rats

(Mean values with their standard errors, $n 5$ )

\begin{tabular}{|c|c|c|c|c|c|c|c|c|c|c|}
\hline & \multicolumn{2}{|c|}{$\mathrm{CONT}^{*}$} & \multicolumn{2}{|c|}{$\mathrm{S} 1$} & \multicolumn{2}{|c|}{$\mathrm{S} 2$} & \multicolumn{2}{|c|}{ S6 } & \multicolumn{2}{|c|}{ P3† } \\
\hline & Mean & SE & Mean & SE & Mean & SE & Mean & SE & Mean & SE \\
\hline Initial body mass $(\mathrm{g})$ & 252.9 & $3 \cdot 3$ & $253 \cdot 1$ & $2 \cdot 8$ & $246 \cdot 4$ & $6 \cdot 2$ & $252 \cdot 2$ & $3 \cdot 1$ & $249 \cdot 0$ & $3 \cdot 2$ \\
\hline Final body mass (g) & $252 \cdot 9^{a}$ & $3 \cdot 3$ & $235 \cdot 1^{a, b}$ & $2 \cdot 3$ & $219 \cdot 3^{b}$ & $5 \cdot 6$ & $182 \cdot 7^{c}$ & 2.5 & $166 \cdot 6^{\mathrm{c}}$ & $5 \cdot 4$ \\
\hline \multicolumn{11}{|c|}{ Organ mass (g, wet wt) } \\
\hline Cerebrum & $1 \cdot 29$ & 0.02 & $1 \cdot 30$ & 0.01 & $1 \cdot 28$ & 0.01 & $1 \cdot 27$ & 0.02 & $1 \cdot 23$ & 0.03 \\
\hline Heart & $0.84^{a}$ & 0.04 & $0.87^{a}$ & 0.03 & $0 \cdot 81^{a}$ & 0.04 & $0.66^{b}$ & 0.02 & $0.58^{b}$ & 0.02 \\
\hline Lungs & $1 \cdot 28$ & 0.08 & $1 \cdot 19$ & $0 \cdot 10$ & 1.09 & 0.06 & 1.09 & 0.13 & 0.95 & 0.06 \\
\hline Stomach & $1 \cdot 16$ & 0.02 & $1 \cdot 15$ & 0.04 & $1 \cdot 14$ & 0.04 & $1 \cdot 20$ & 0.05 & $1 \cdot 19$ & 0.08 \\
\hline Kidneys & $1.94^{a}$ & 0.05 & $1 \cdot 89^{a, b}$ & 0.6 & $1.69^{b, c}$ & 0.03 & $1.53^{\mathrm{c}, \mathrm{d}}$ & 0.02 & $1.43^{d}$ & 0.04 \\
\hline Spleen & $0.75^{a}$ & 0.04 & $0.67^{a}$ & 0.03 & $0.50^{a}$ & 0.05 & $0.30^{b}$ & 0.01 & $0.25^{c}$ & 0.04 \\
\hline Testes & $2 \cdot 75^{\mathrm{a}, \mathrm{b}}$ & 0.07 & $2 \cdot 66^{\mathrm{b}, \mathrm{c}}$ & 0.05 & $2 \cdot 66^{\mathrm{b}, \mathrm{c}}$ & 0.04 & $2 \cdot 47^{\mathrm{b}, \mathrm{c}}$ & 0.03 & $2.45^{c}$ & 0.06 \\
\hline Liver & $11 \cdot 18^{\mathrm{a}}$ & 0.23 & $7 \cdot 25^{\mathrm{b}}$ & 0.22 & $6 \cdot 07^{\mathrm{b}}$ & 0.19 & $4 \cdot 69^{c}$ & 0.12 & $3.83^{C}$ & 0.42 \\
\hline
\end{tabular}

CONT, non-starved control rats; S1, 1-day starved rats; S2, 2-day starved rats; S6, 6-day starved rats; P3, starved to phase 3 rats.

a,b,c Mean values within a row with unlike superscript letters were significantly different determined by one-way ANOVA with Tukey's multiple comparison tests $(P<0.05)$.

* Since the control rats were killed at the beginning of the experiment, the initial body weight was same as the final body weight.

$\dagger$ Phase 3 is determined by the rapid increase in $\mathrm{d} M / \mathrm{d} M$ t (refer to Fig. 1). 


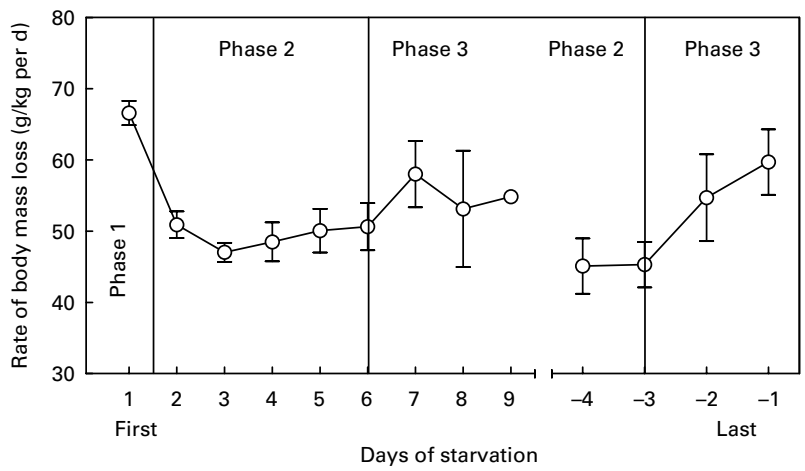

Fig. 1. Rate of body mass loss $(\mathrm{d} M / M \mathrm{~d} t)$ in starved rats. Values are means with their standard errors ( $n 1-20$ per $\mathrm{d}$ in the left; $n 5$ per $\mathrm{d}$ in the right). $\mathrm{d} M / M \mathrm{~d} t$ ( $\mathrm{d} M$ represents the loss of body mass during $\mathrm{d} t=t_{1}-t_{0}$ and $M$ is the body mass of rat at $t_{0}$ ) was calculated for each animal. Abscissa: left, days counted from the beginning of starvation in all rats; right, counted to the end of starvation in the P3 group.

sharp decrease during the first hours of starvation and a steady rate at days 2-6 of starvation. Since obvious rapid increase was not observed after day 7 of starvation, we showed that the last part of starvation was counted to the end of starvation in the $\mathrm{P} 3$ group. The $\mathrm{d} M / \mathrm{d} M t$ in the $\mathrm{P} 3$ group clearly showed a rapid increase from $3 \mathrm{~d}$ before the end of starvation. These patterns were exactly consistent with previous reports ${ }^{(10,14)}$. Therefore, we defined the phase at first decrease as phase 1, that of steady rate as phase 2 and the third part of the curve as phase 3 according to previous reports ${ }^{(10,14)}$. The $\$ 6$ group showed the steady rate of body mass loss and the low blood 3-HBA concentration, and these were characteristics of both phases 2 and 3. These results showed that the S1 group was representative of phase 1, the S2 was of phase 2, the $\mathrm{S} 6$ group was in the marginal range between phases 2 and 3, and the $\mathrm{P} 3$ group was in phase 3 .

\section{Changes in mass of individual organs during starvation}

Table 2 shows the changes in the mass of individual organs during starvation. The cerebrum, lung and stomach mass was not affected by starvation. The liver weight was gradually reduced by starvation, and that in the $\mathrm{P} 3$ group was $30 \%$ of the control group. From $2 \mathrm{~d}$ of starvation, kidney mass decreased. Heart and spleen mass decreased from $6 \mathrm{~d}$. Testes mass decreased in P3 rats. Prolonged starvation reduced the spleen and liver weight the most.

\section{Blood/plasma parameters}

Table 3 shows the blood parameters. Blood 3-HBA increased more in S1 and S2 rats than in control rats. In contrast, the urea concentration in plasma was significantly higher in S6 and P3 rats, whereas there was a non-significant increase in the S1 and S2 rats. Plasma glucose level was $60 \%$ significantly lower in the S1, S2 and S6 rats than in the control rats. Interestingly, plasma glucose returned to the basal level in the P3 rats. Plasma TAG was dramatically decreased after $1 \mathrm{~d}$ of starvation and then continued to decrease gradually throughout the remainder of the starvation period. Plasma aspartate aminotransferase was not affected by starvation. Plasma alanine aminotransferase began to increase after $6 \mathrm{~d}$ of starvation.

\section{Effect of starvation on vitamin status}

Table 4 shows B-group vitamin content in tissue, blood and urine in the control rats. We determined the B-group vitamin contents in nine tissues including the cerebrum, heart, lung, stomach, kidney, spleen, testis, skeletal muscle and liver, and five tissues were selected as representative variations in Fig. 2.

Cerebrum (Fig. 2(A)) and spleen. With the exception of biotin, all vitamin concentrations were unchanged by starvation. Biotin concentration was initially elevated to $150 \%$ in the S1 rats, and then returned to basal level. B-group vitamin concentrations in the spleen showed a similar pattern that starvation did not affect their concentrations except for vitamin $\mathrm{B}_{2}$. Vitamin $\mathrm{B}_{2}$ concentration in the testis was elevated to $130 \%$ after $6 \mathrm{~d}$ of starvation.

Heart (Fig. 2(B)). Vitamin $\mathrm{B}_{1}$ and folate concentrations significantly decreased to approximately $60 \%$ after $6 \mathrm{~d}$ of starvation. Pantothenic acid concentration was significantly lower in the S2 and S6 rats than in the control rats. Biotin and vitamin $\mathrm{B}_{6}$ concentrations significantly increased to 160 and $250 \%$ in the S1 and S6 rats, respectively. The other B-group vitamin concentrations were unchanged.

Table 3. Blood parameters in the control and starved rats

(Mean values with their standard errors, $n 5$ )

\begin{tabular}{|c|c|c|c|c|c|c|c|c|c|c|}
\hline & \multicolumn{2}{|c|}{ CONT } & \multicolumn{2}{|c|}{ S1 } & \multicolumn{2}{|c|}{ S2 } & \multicolumn{2}{|c|}{ S6 } & \multicolumn{2}{|c|}{ P3 } \\
\hline & Mean & SE & Mean & SE & Mean & SE & Mean & SE & Mean & SE \\
\hline 3-HBA $(\mathrm{mmol} / \mathrm{l})^{*}$ & $0.1^{\mathrm{a}}$ & 0.0 & $1.8^{\mathrm{a}}$ & 0.1 & $2 \cdot 5^{\mathrm{b}}$ & 0.2 & $0.7^{\mathrm{a}}$ & 0.1 & $0.3^{a}$ & 0.1 \\
\hline Glucose $(\mathrm{mmol} / \mathrm{l})$ & $6 \cdot 36^{a}$ & 0.28 & $3.86^{\mathrm{b}}$ & 0.32 & $3.84^{\mathrm{b}}$ & 0.29 & $3 \cdot 71^{\mathrm{b}}$ & 0.37 & $6 \cdot 44^{\mathrm{a}}$ & 0.60 \\
\hline TAG $(\mathrm{mmol} / \mathrm{l})$ & $3.01^{a}$ & 0.45 & $0.82^{b}$ & 0.08 & $0.81^{b}$ & 0.07 & $0.54^{\mathrm{b}}$ & $0 \cdot 10$ & $0.46^{\mathrm{b}}$ & 0.05 \\
\hline Urea $(\mathrm{mmol} / \mathrm{l})$ & $7 \cdot 45^{\mathrm{a}}$ & 0.27 & $6 \cdot 21^{a}$ & 0.42 & $6 \cdot 21^{a}$ & 0.30 & $8 \cdot 23^{\mathrm{b}}$ & $2 \cdot 36$ & $13.08^{b}$ & 0.68 \\
\hline AST (U/I) & 263 & 21 & 245 & 10 & 242 & 21 & 240 & 10 & 252 & 8 \\
\hline ALT (U/I) & $39 \cdot 8^{a}$ & 3.8 & $29 \cdot 4^{a}$ & 1.9 & $31 \cdot 8^{a}$ & 1.8 & $65 \cdot 5^{\mathrm{b}}$ & $10 \cdot 0$ & $73 \cdot 3^{b}$ & 5.9 \\
\hline
\end{tabular}

CONT, non-starved control rats; S1, 1-day starved rats; S2, 2-day starved rats; S6, 6-day starved rats; P3, starved to phase 3 rats; 3-HBA, 3-hydroxybutyrate; AST aspartate aminotransferase; ALT, alanine aminotransferase.

a,b Mean values within a row with unlike superscript letters were significantly different determined by one-way ANOVA with Tukey's multiple comparison tests $(P<0 \cdot 05)$.

* 3 -HBA was measured in whole blood, and the others in serum. 

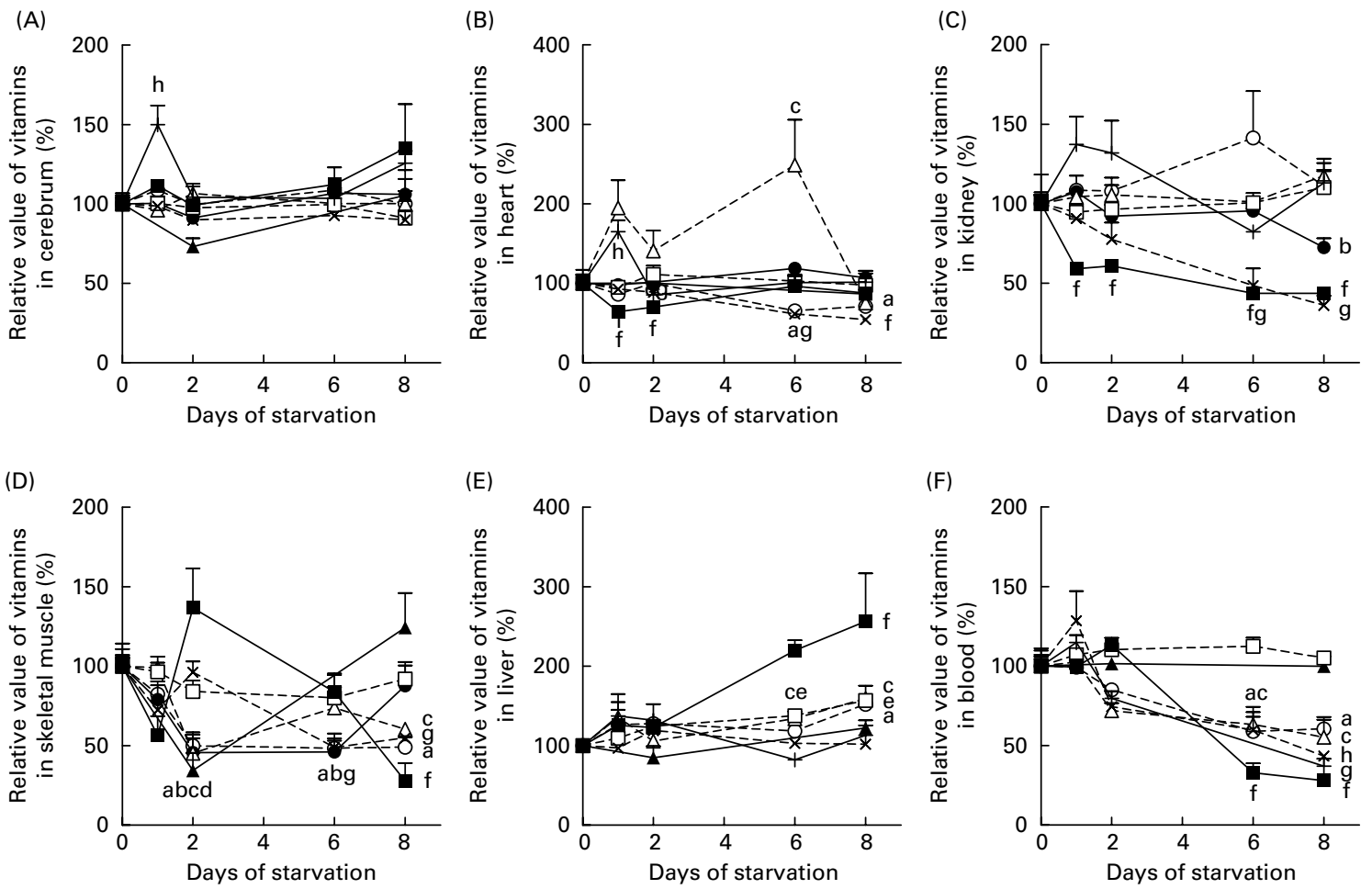

Fig. 2. Relative value of $B$-group vitamin concentrations in (A) cerebrum, $(B)$ stomach, $(C)$ kidney, (D) skeletal muscle, (E) liver and (F) blood of rats during starvation. * Sum of serum pyridoxal and pyridoxal-5'-phosphate is expressed as serum vitamin $\mathrm{B}_{6}$. Values are reported as means with their standard errors, $n 5$ per d. Values of control rats are expressed as $100 \%$. P3 is expressed at $8 \mathrm{~d}$ of starvation. Means with unlike letters were significantly different from day 0 in ${ }^{a}$ vitamin $\mathrm{B}_{1}(\bigcirc)$, ${ }^{\mathrm{b}}$ vitamin $\mathrm{B}_{2}(\bullet)$, ${ }^{\mathrm{c}}$ vitamin $\mathrm{B}_{6}{ }^{*}(\Delta),{ }^{\mathrm{d}}$ vitamin $\mathrm{B}_{12}(\boldsymbol{\Delta}),{ }^{\mathrm{e}}$ nicotinamide $(\square),{ }^{\mathrm{f}}$ pantothenic acid $(\boldsymbol{\square}),{ }^{9}$ folate $(\times)$ and ${ }^{\mathrm{h}}$ biotin $(+; P<0.05)$.

Kidney (Fig. 2(C)) and testis. Pantothenic acid concentration dramatically decreased to $50 \%$ of control during starvation. Folate concentration significantly decreased to $40 \%$ in the $\mathrm{S} 6$ and $\mathrm{P} 3$ rats. Vitamin $\mathrm{B}_{2}$ concentration significantly decreased to $70 \%$ in the $\mathrm{P} 3$ rats. The reduction in pantothenic acid concentration from day 1 of starvation was also observed in the stomach and testis, and their maximal reduction was $60 \%$. In the testis, vitamin $\mathrm{B}_{2}$ concentration also significantly reduced to $50 \%$ during starvation, and other vitamin concentrations were not changed.

Skeletal muscle (Fig. 2(D)) and stomach. Concentrations of vitamin $\mathrm{B}_{1}$, vitamin $\mathrm{B}_{2}$ and vitamin $\mathrm{B}_{6}$ significantly decreased to $50 \%$ from $2 \mathrm{~d}$ of starvation, but only vitamin $\mathrm{B}_{2}$ concentration returned to control levels in the $\mathrm{P} 3$ rats. Vitamin $\mathrm{B}_{12}$ concentration significantly decreased to $40 \%$ only in the S2 rats. Pantothenic acid concentration significantly decreased in the $\mathrm{P} 3$ rats. Folate concentration significantly decreased to $50 \%$ in the S6 and P3 rats. Pantothenic acid concentration was same as control until $6 \mathrm{~d}$ of starvation, and then dramatically decreased to $30 \%$ in the P3 rats. Similar pattern was observed in the stomach that starvation reduced several B-group vitamin concentrations. In brief, pantothenic acid and biotin concentrations reduced to 30 and $60 \%$ from day 1 of starvation, respectively. Vitamin $\mathrm{B}_{6}$ concentration significantly decreased to $50 \%$ from day 2 , and vitamin $\mathrm{B}_{2}$ did to $40 \%$ from day 6 of starvation.

Liver (Fig. 2(E)). Vitamin $\mathrm{B}_{6}$ concentration was significantly higher in the $\mathrm{S} 1, \mathrm{~S} 6$ and $\mathrm{P} 3$ rats, and the relative value in the $\mathrm{P} 3$ rats was $160 \%$ of the control animals. Nicotinamide concentration increased in the S2, S6 and P3 rats. Vitamin $\mathrm{B}_{1}$ and pantothenic acid concentrations were higher in the $\mathrm{P} 3$ rats, and their values were 150 and $250 \%$, respectively. Other B-group vitamins concentrations were unchanged.

Blood (Fig. 2(F)). Whole blood vitamin $\mathrm{B}_{1}$, serum vitamin $\mathrm{B}_{6}$ and plasma pantothenic acid concentrations decreased in the S6 and P3 rats. Plasma folate and biotin concentrations decreased in the $\mathrm{P} 3$ rats. The relative values of vitamin $\mathrm{B}_{1}$ and vitamin $\mathrm{B}_{6}$ in the $\mathrm{P} 3$ rats were $60 \%$ of control, those of folate and biotin were $50 \%$, and those of pantothenic acid were $30 \%$.

Urinary contents of B-group vitamins (Fig. 3). Vitamin $\mathrm{B}_{1}$ excretion acutely decreased to $10 \%$ after $1 \mathrm{~d}$ of starvation. Urinary excretion of riboflavin, pyridoxal metabolite 4-pyridoxic acid and vitamin $\mathrm{B}_{12}$ gradually decreased during $4 \mathrm{~d}$ of starvation. Subsequently these values were stable, at approximately 20, 20 and $50 \%$ of each control value. Urinary folate was initially unchanged in the S1 rats and then decreased to $40 \%$ of the baseline value. Urinary pantothenic acid was increased to $170 \%$ in 3 rd and 4 th days of starvation, and then returned to the control level. Although biotin excretion increased to $460 \%$ during the first $3 \mathrm{~d}$ of starvation, it subsequently returned to the basal level.

Urinary contents of nicotinamide and its catabolites (Fig. 4). Nicotinamide excretion increased after $1 \mathrm{~d}$ of starvation and then returned to the basal level. 2-Py and 4-Py decreased after an initial increase on day 1. In contrast, MNA excretion 
increased during the starvation period. Urinary excretion of the sum of nicotinamide and its catabolites increased 1.4fold after $1 \mathrm{~d}$ of starvation and then decreased by less than half of the food sufficient state.

\section{Discussion}

The effects of metabolic changes, which are designated as the changes in the main energy sources such as glucose, lipids and protein, during starvation on the tissue and urine vitamin concentrations are currently poorly understood ${ }^{(11)}$. Elucidation of the effects will lead to a suitable supplementation for preventing the refeeding syndrome. Therefore, we investigated the effects of short- and long-term starvation on the vitamin concentrations in organs, muscle, blood and urine in rats.

Vitamin concentrations in organs and muscle showed different patterns for each vitamin. For noticeable characteristics, biotin concentration, which means the value in terms of $g$ tissue, was increased in most organs of the S1 rats. A part of the reason is a reduced organ mass at S1. It was unclear why the biotin concentrations in organs remained at the same level regardless of organ mass during starvation. Vitamin $\mathrm{B}_{1}$ is the vitamin that has the most rapid turnover ${ }^{(30)}$, but the levels in the kidney were maintained. This may point to the necessity of vitamin $B_{1}$ in kidneys of starving rats. In terms of the metabolic state, vitamin $B_{1}$ was expected to decrease in the early days of starvation, because glucid is the main energy source in this period ${ }^{(3)}$. However, vitamin $\mathrm{B}_{1}$ concentrations in tissues and blood were stable in the $\mathrm{S} 1$ rats. This is due to the sharp decrease in liver weight and in the urinary excretion of vitamin $\mathrm{B}_{1}$. Along with the shifts in the main energy source from glucid to fat, vitamin demands appear to change. Next to vitamin $B_{1}$, pantothenic acid requirement may be the highest because it is involved in the metabolism of fatty acids ${ }^{(31)}$, and also, biotin requirement may be higher because the gluconeogenesis is more active at the deficient state of glucose ${ }^{(32)}$. However, the present results were contrary to our expectations. Pantothenic acid concentrations in the heart, stomach, kidneys and testes were decreased in the S1 rats, and a similar phenomenon was observed in biotin concentrations. The urinary excretion of pantothenic acid and biotin was significantly increased by starvation. A similar phenomenon was already reported by Fukuwatari et al. ${ }^{(30)}$. Shibata and co-workers reported ${ }^{(33-38)}$ that the urinary excretion of water-soluble vitamins reflects recent intake of the vitamins over the last few days, and in addition, the decreased urinary excretion of vitamins means the elevated demand for vitamins, whereas the increased urinary excretion of vitamins means the reduced demand for vitamins when their intake of vitamins is almost the same ${ }^{(33)}$. The increased urinary excretion suggests that the requirement of pantothenic acid and biotin was reduced by starvation, that is, lower concentrations of pantothenic acid and biotin in the body might prefer to live for a long time during starvation. A possible inferable reason for the increase in urinary pantothenic acid and biotin might be a mechanism to prevent the stored fat in the body from overspending or to decrease the amount of acetyl-coenzyme A, 
(A)

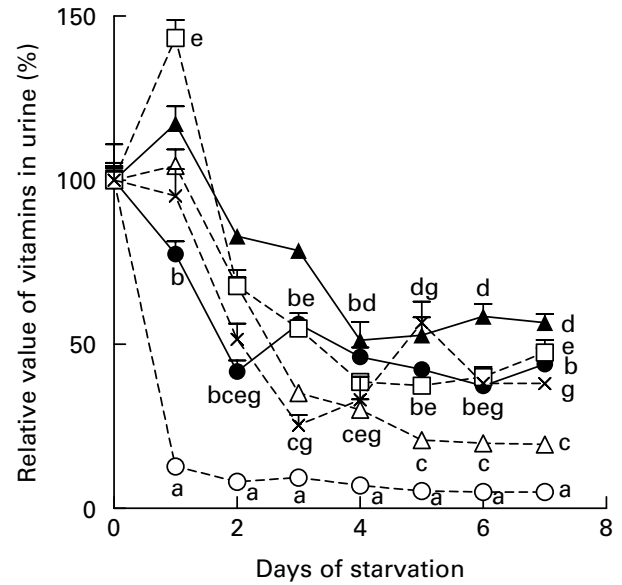

(B)

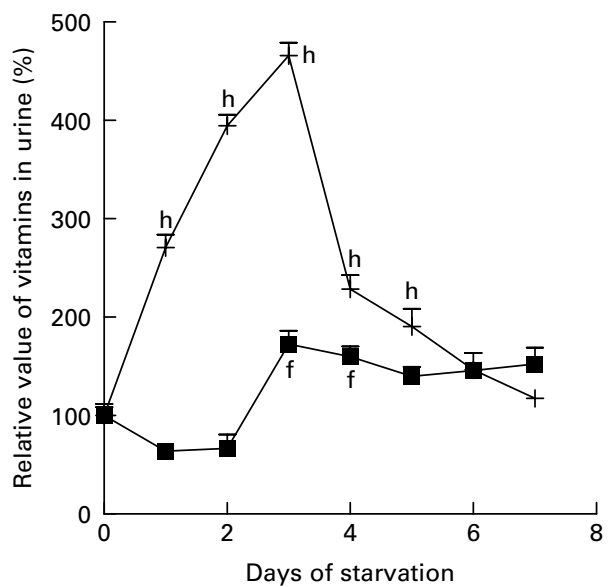

Fig. 3. Relative value of urinary $B$-group vitamin contents in $P 3$ rats during starvation. Those of vitamin $B_{1}$, vitamin $B_{2}$, vitamin $B_{6}$, vitamin $B_{12}$, nicotinamide and folate are shown in (A), and pantothenic acid and biotin in (B). Thiamin is expressed as vitamin $B_{1}$, riboflavin as vitamin $B_{2}$, 4-pyridoxic acid as vitamin $B_{6}$, and sum of nicotinamide and its catabolites as nicotinamide. Values are reported as means with their standard errors, $n 5$ per $d$. Values of control rats are expressed as $100 \%$. P3 is expressed at $8 \mathrm{~d}$ of starvation. Means with unlike letters were significantly different from day 0 in ${ }^{a}$ vitamin $B_{1}(O),{ }^{b}$ vitamin $B_{2}(\bullet),{ }^{C}$ vitamin $B_{6}{ }^{*}(\Delta)$, ${ }^{d}$ vitamin $\mathrm{B}_{12}(\mathbf{\Lambda})$, ${ }^{\mathrm{e}}$ nicotinamide $(\square),{ }^{\mathrm{f}}$ pantothenic acid $(\square),{ }^{9}$ folate $(\times)$ and ${ }^{\mathrm{h}}$ biotin $(+; P<0.05)$.

which modifies several functional proteins such as histone (39) $^{3}$ and some enzymes ${ }^{(40)}$, and in addition, to decrease holoenzymes of carboxylases ${ }^{(41,42)}$. Acetylation generally activated some enzymes in fatty acid oxidation ${ }^{(40)}$. The physiologically active form of biotin is covalently attached at the active site of a class of important metabolic enzymes in gluconeogenesis,

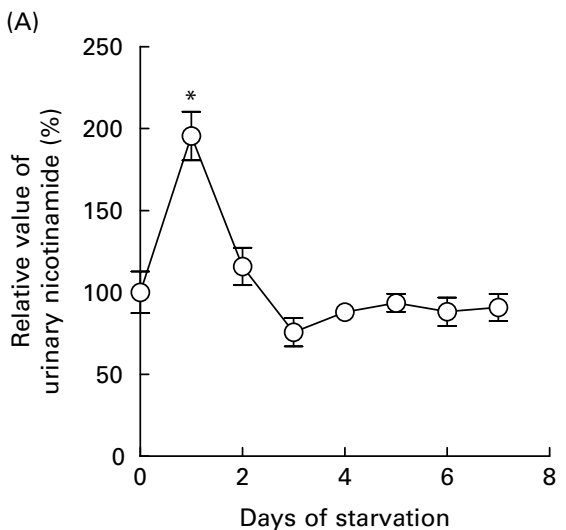

(C)

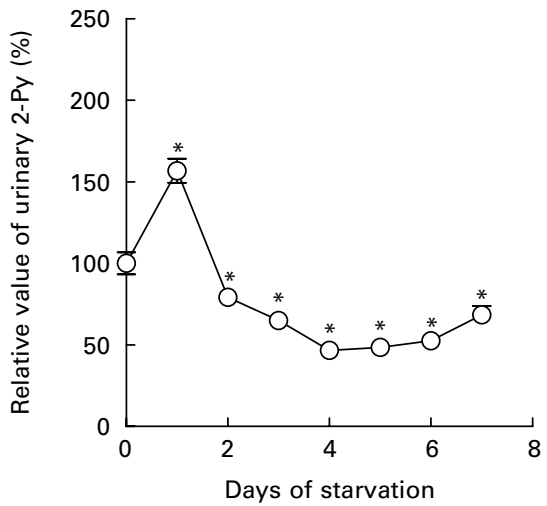

lipogenesis and amino acid metabolism ${ }^{(41,42)}$. Accordingly, decreased acetylation and biotin-dependent enzymes lead to reduced fatty acid oxidation and to save fat in the body.

Vitamin $\mathrm{B}_{6}$ concentrations, expected to be the last vitamin decreased in tissues by starvation ${ }^{(3)}$, decreased in the stomach, skeletal muscle and serum of the $\mathrm{S} 2$ rats. Vitamin $\mathrm{B}_{6}$ in the

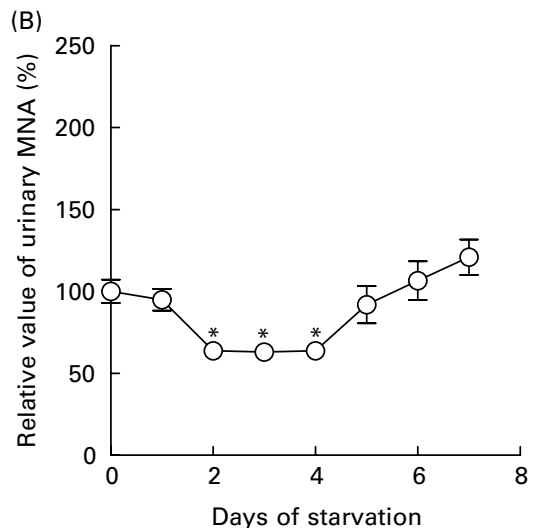

(D)

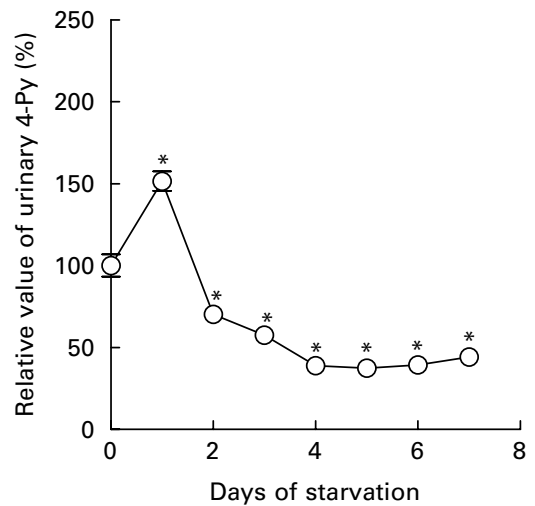

Fig. 4. Relative value of urinary nicotinamide (a) and its catabolites MNA (b), 2-Py (c) and 4-Py (d) contents in P3 rats during starvation. Values are reported as means with their standard errors, $n 5$ per $\mathrm{d}$. * Mean values were significantly different from day 0 determined by one-way ANOVA with Tukey's multiple comparison tests $\left(P<0\right.$-05). MNA, $N^{1}$-methylnicotinamide; 2-Py, $N^{1}$-methyl-2-pyridone-5-carboxamide; 4-Py, $N^{1}$-methyl-4-pyridone-3-carboxamide. 
lung and serum decreased in the $\mathrm{S} 6$ rats. The differences in the pattern of vitamin $\mathrm{B}_{6}$ decline may be due to the fat content of each tissue. Nicotinamide concentrations in tissues and blood were unchanged by starvation, despite this vitamin being involved in energy metabolism. Since nicotinamide is biosynthesised from tryptophan ${ }^{(43)}$, nicotinamide concentrations in organs and blood were maintained. Urinary excretion of the sum of nicotinamide and its catabolites was high after $1 \mathrm{~d}$ of starvation and subsequently decreased. These results are in agreement with those reported by a previous study ${ }^{(30)}$. The proportion of nicotinamide, MNA, 2-Py and 4-Py in urine is controlled by enzymes involved in the metabolism of tryptophan to niacin. Starvation or food restriction induces a decline in MNA oxidase activity ${ }^{(44)}$ and an elevation in nicotinamide methyltransferase ${ }^{(44)}$. This may explain why levels of 2-Py and 4-Py in urine decreased while those of MNA increased. MNA is an inhibitor of nicotinamide methyltransferase ${ }^{(45)}$. Therefore, an accumulation of MNA inhibits the activity of nicotinamide methyltransferase and leads to an increase in free form of nicotinamide, which inhibits the activities of histone deacetylase ${ }^{(46)}$ and poly(ADP-ribose) synthetase $^{(47)}$. This control might be suitable for living long during starvation.

To our knowledge, the present study presents the first data on vitamin status during the three phases of starvation. The changes in B-group vitamin concentrations in tissues and blood did not always correspond to metabolic states. The changes in vitamin content can be divided into three groups. First, vitamin $\mathrm{B}_{1}$, vitamin $\mathrm{B}_{2}$, nicotinamide and biotin levels declined gradually. Second, vitamin $\mathrm{B}_{6}$ and vitamin $\mathrm{B}_{12}$ levels rapidly decreased after $1 \mathrm{~d}$ of starvation and then remained at a steady level. Finally, pantothenic acid and folate initially decreased in the S1 rats, then returned to near basal levels in the next day of starvation, then subsequently decreased again. This might mean that pantothenic acid and folate were mobilised to other tissues. We are unsure why such complicated changes occur. It is clear that further investigation, such as separate measurement of the free forms of the vitamins and of coenzymes, into the changes in the vitamin requirements of starving rats would be useful for the prevention of vitamin deficiency during starvation or for consequent refeeding.

\section{Acknowledgements}

The present study was supported by a Research Grant for Comprehensive Research on Cardiovascular and Lifestyle Related Diseases from the Ministry of Health, Labour and Welfare of Japan. The title of the project was 'Studies on Construction of Evidence to revise the Dietary Reference Intakes for Japanese - Elucidation of balance between macronutrient and micronutrient' (Principal Investigator, K. S.). A. M. and T. F. were responsible for designing the study strategies, retrieving the references and writing the manuscript. M. S. participated in retrieving references and critical reading. K. S. directed and designed the study. The authors have no conflict of interests to report.

\section{References}

1. Robin J-P, Decrock F, Herzberg G, et al. (2008) Restoration of body energy reserves during refeeding in rats is dependent on both the intensity of energy restriction and the metabolic status at the onset of starvation. J Nutr 138, 861-866.

2. Li R-Y, Zhang Q-H, Liu Z, et al. (2006) Effect of short-term and long-term fasting on transcriptional regulation of metabolic genes in rat tissues. Biochem Biophys Res Commun 344, 562-570.

3. Cherel Y, Robin JP \& Maho LY (1988) Physiology and biochemistry of long-term fasting in birds. Can J Zool 66 , 159-166.

4. Koubi HE, Robin JP, Gewasmes G, et al. (1991) Fastinginduced rise in locomotor activity in rats coincides with increased protein utilization. Physiol Behav 50, 337-343.

5. Goodman MN, Larsen PR, Kaplan MN, et al. (1980) Starvation in the rat. II. Effect of age and obesity on protein sparing and fuel metabolism. Am J Physiol 239, E277-E286.

6. Le Maho Y, Vu Van Kha H, Koubi H, et al. (1981) Body composition, energy expenditure, and plasma metabolites in long-term fasting geese. Am J Physiol 41, E342-E354.

7. Cherel Y \& Le Maho Y (1985) Five months of fasting in king penguin chicks, body mass loss and fuel metabolism. Am J Physiol 249, R387-R392.

8. Le Maho Y, Vu Van Kha H, Koubi H, et al. (1976) Thermoregulation in fasting emperor penguins under natural conditions. Am J Physiol 231, 913-922.

9. Robin J-P, Cherel Y, Girard H, et al. (1987) Uric acid and urea in relation to protein catabolism in long-term fasting geese. J Comp Physiol B 157, 491-499.

10. Le Maho Y, Vu Van Kha H, Koubi H, et al. (1981) Body composition, energy expenditure, and plasma metabolites in long-term fasting geese. Am J Physiol 241, E342-E354.

11. Kraft MD, Btaiche IF \& Sacks GS (2005) Review of the refeeding syndrome. Nutr Clin Pract 20, 625-633.

12. Dietary Reference Intakes for Japanese (2010) Dietary Reference Intakes for Japanese. Tokyo: Ministry of Health, Labour, and Welfare, Japan; 2009.

13. Reeves PG, Nielsen FH \& Fahey GC Jr (1993) AIN-93 purified diets for laboratory rodents: final report of the American Institute of Nutrition ad hoc writing committee on the reformulation of AIN-76A rodent diet. J Nutr 123, 1939-1951.

14. Habold C, Chevalier C, Dunel-Erb S, et al. (2004) Effects of fasting and refeeding on jejuna morphology and cellular activity in rats in relation to depletion of body stores. Scand J Gastroenterol 39, 531-539.

15. Fukuwatari T, Suzuura C, Sasaki R, et al. (2004) Action site of bisphenol A as metabolic disruptor lies in the tryptophannicotinamide conversion pathway. J Food Hyg Soc Japan 45, 231-238.

16. Ohkawa H, Ohishi N \& Yagi K (1983) New metabolites of riboflavin appear in human urine. $J$ Biol Chem 258, 5623-5628.

17. Ohakawa H, Ohishi N \& Yagi K (1982) A simple method for micro-determination of flavin in human serum and whole blood by high-performance liquid chromatography. Biochem Int 4, 187-194.

18. Gregory JF 3rd \& Kirk JR (1979) Determination of urinary 4-pyridoxic acid using high performance liquid chromatography. Am J Clin Nutr 32, 879-883.

19. Rybak ME \& Pfeiffer CM (2004) Clinical analysis of vitamin $\mathrm{B}_{6}$ : determination of pyridoxal $5^{\prime}$-phosphate and 4-pyridoxic acid in human serum by reversed-phase high-performance liquid chromatography with chlorite postcolumn derivatization. Anal Biochem 333, 336-344. 
20. Association of Official Analytical Chemists (2000) Official Methods of Analysis, 17th ed. Arlington, VA: AOAC, Inc.

21. Watanabe F, Katsura H, Takenaka S, et al. (1999) Pseudovitamin $B_{12}$ is the predominant cobamide of an algal health food, spirulina tablets. J Agric Food Chem 47, 4736-4741.

22. Shibata K, Kawada T \& Iwai K (1988) Simultaneous microdetermination of nicotinamide and its major metabolites, $N^{1}$-methyl-2-pyridone-5-carboxamide and $N^{1}$-methyl-3-pyridone-4-carboxamide, by high-performance liquid chromatography. J Chromatogr 424, 23-28.

23. Shibata K (1987) Ultramicro-determination of $N^{1}$-methylnicotinamide in urine by high-performance liquid chromatography. Vitamins (Japan) 61, 599-604.

24. Shibata K (1987) High-performance liquid chromatographic determination of nicotinamide in rat tissue samples and blood after extraction with diethyl ether. J Chromatogr 422, 257-262.

25. Takahashi K, Fukuwatari T \& Shibata K (2009) Fluorometric determination of pantothenic acid in human urine by isocratic reversed-phase ion-pair high-performance liquid chromatography with post-column derivatization. J Chromatogr $B \mathbf{8 7 7}, 2168-2172$.

26. Skeggs HR \& Wright LD (1944) The use of Lactobacillus arabinosus in the microbiological determination of pantothenic acid. $J$ Biol Chem 156, 21-26.

27. Aiso K \& Tamura T (1998) Trienzyme treatment for food folate analysis. Optimal $\mathrm{pH}$ and incubation time for $\alpha$-amylase and protease treatment. J Nutr Sci Vitaminol 44, 361-370.

28. Fukui T, Iinuma K, Oizumi J, et al. (1994) Agar plate method using Lactobacillus plantarum for biotin determination in serum and urine. J Nutr Sci Vitaminol 40, 491-498.

29. Cherel Y, Burnol A-F, Leturque A, et al. (1988) In vivo glucose utilization in rat tissues during the three phases of starvation. Metabolism 37, 1033-1039.

30. Fukuwatari T, Yoshida E, Takahashi K, et al. (2010) Effect of fasting on the urinary excretion of water-soluble vitamins in humans and rats. J Nutr Sci Vitaminol 56, 19-26.

31. Wittwer CT, Beck S, Peterson M, et al. (1990) Mild pantothenate deficiency in rats elevates serum triglyceride and free fatty acid levels. J Nutr 120, 719-725.

32. Bannister DW (1976) The biochemistry of fatty liver and kidney syndrome. Biotin-mediated restoration of hepatic gluconeogenesis in vitro and its relationship to pyruvate carboxylase activity. Biochemistry J 156, 167-173.

33. Fukuwatari T \& Shibata K (2008) Urinary water-soluble vitamin and their metabolites contents as nutritional markers for evaluating vitamin intakes in young Japanese women. J Nutr Sci Vitaminol 54, 223-229.
34. Shibata K, Fukuwatari T, Watanabe T, et al. (2009) Intra- and inter-individual variations of blood and urinary watersoluble vitamins in Japanese young adults consuming a semi-purified diet for 7 days. J Nutr Sci Vitaminol 55, 459-470.

35. Fukuwatari T, Sugimoto E, Tsuji T, et al. (2009) Urinary excretion of vitamin $B_{12}$ depends on urine volume in female university students and elderly subjects in Japan. Nutr Res 29, 839-845.

36. Tsuji T, Fukuwatari T, Sasaki S, et al. (2010) Urinary excretion of vitamin $\mathrm{B}_{1}, \mathrm{~B}_{2}, \mathrm{~B}_{6}$, niacin, pantothenic acid, folate, and vitamin $\mathrm{C}$ correlates with dietary intakes of free-living elderly, female Japanese. Nutr Res 30, 171-178.

37. Tsuji T, Fukuwatari T, Sasaki S, et al. (2010) Twenty-fourhour urinary water-soluble vitamins correlate to vitamin intakes in free-living Japanese university students. Eu J Clin Nutr 64, 800-807.

38. Tsuji T, Fukuwatari T, Sasaki S, et al. (2011) Twenty-fourhour urinary water-soluble vitamin levels correlate with their intakes in free-living Japanese school children. Public Health Nutr 14, 27-33.

39. Alcarraz-Vizán G, Boren J, Lee W-NP, et al. (2010) Histone deacetylase inhibition results in a common metabolic profile associated with HT29 differentiation. Metabolomics 6, $229-237$.

40. Zhao S, Xu W, Jiang W, et al. (2010) Regulation of cellular metabolism by protein lysine acetylation. Science 327, 1000-1004.

41. Samols D, Thornton CG, Murtif VL, et al. (1988) Evolutionary conservation among biotin enzymes. J Biol Chem 263, 6461-6464.

42. Knowles JR (1989) The mechanism of biotin-dependent enzymes. Annu Rev Biochem 58, 195-221.

43. Gholson RK, Ueda I, Ogasawara N, et al. (1963) The enzymatic conversion of quinolinate to nicotinic acid mononucleotide in mammalian liver. J Biol Chem 239, 1208-1214.

44. Shibata K, Kondo T \& Miki A (1998) Increased conversion ratio of tryptophan to niacin in severe food restriction. Biosci Biotech Biochem 62, 580-583.

45. Aksoy S, Szumlanski CL \& Weinshilboum RM (1994) Human liver nicotinamide $\mathrm{N}$-methyltransferase. cDNA cloning, expression, and biochemical characterization. J Biol Chem 269, 14835-14840

46. Gallo CM, Smith DL \& Smith JS (2004) Nicotinamide clearance bu Pnc1 directly regulates Sir2-mediated silencing and longevity. Mol Cell Biol 24, 1301-1312.

47. Banasik M, Komura H, Shimoyama M, et al. (1992) Specific inhibitors of poly(ADP-ribose) synthetase and mono(ADPribosyl)transferase. J Biol Chem 267, 1569-1575. 